\title{
LA HUELLA DE GALDÓS EN LA NOVELA SOCIAL ESPAÑOLA CONTEMPORÁNEA
}

\author{
María del Mar López Cabrera 1 \\ Doctora en Filología - Centenario Galdós 2020 - Las Palmas de Gran Canaria \\ Departamento de Lengua Castellana y Literatura, IES La Isleta (Las Palmas de GC)
}

https://doi.org/10.33676/EMUI_nomads.61.05

Resumen: En este trabajo pretendemos exponer cómo el compromiso formulado por Galdós de retratar la sociedad que le rodea, mostrar sus defectos e intentar encontrar fórmulas para mejorarla, caló hondo en algunos novelistas sociales españoles contemporáneos como Juan Marsé, Rafael Chirbes, Almudena Grandes, o Antonio Muñoz Molina, entre otros. Para ello, en primer lugar, presentaremos cuáles eran los principios filosófico-sociales de Benito Pérez Galdós, seguidamente veremos cuál era la importancia que tenían la sociedad y la historia en su literatura, y por último analizaremos la huella galdosiana en los novelistas sociales de nuestro tiempo.

Palabras clave: Benito Pérez Galdós, sociedad, principios filosóficos, huella, novelistas sociales.

\section{The footprint of Galdós In the Contemporary Spanish Social Novel}

Abstract: In this work, we intend to outline how Galdós' commitment to portray the society around him, to show its defects and to try to find ways to improve it, found its way into some contemporary Spanish social novelists such as Juan Marsé, Rafael Chirbes, Almudena Grandes and Antonio Muñoz Molina, among others. To this end, we will first present the philosophical and social principles of Benito Pérez Galdós, then we will see what importance society and history had in his literature, and finally we will analyse the Galdosian imprint on the social novelists of our time.

Key words: Benito Pérez Galdós, society, philosophical principles, imprint, social novelists.

\section{1.- PRINCIPIOS FILOSÓFICO-SOCIALES DE BENITO PÉREZ GALDÓS}

Algunos estudiosos no dudan en incluir a Galdós en las filas del humanismo, aunque añaden que no representa el tipo del humanismo clásico. Su obra ilustra una noción moderna del humanismo resultado de

\footnotetext{
1 Doctora en Filología (UNED, 1995) con Licenciatura previa en Filología (UNED, 1988) y funcionaria de carrera del cuerpo de Profesores de Secundaria (2010), trabajó como documentalista en la Casa-Museo Pérez Galdós (2001-2002) antes de comenzar su actividad docente. En la actualidad tiene su destino definitivo en el IES La Isleta de la capital grancanaria. Ha publicado un resumen de su tesis doctoral, El teatro en Las Palmas de Gran Canaria (1853-1900), y varios artículos; y ha participado en las ediciones IV, $\vee$ y XI del Congreso Internacional de Estudios Galdosianos. En 2008 creó el blog Literatura. Es la autora y tutora on-line de dos cursos de teleformación para docentes de la Consejería de Educación y Universidades del Gobierno de Canarias: "Personajes femeninos de la literatura de Galdós" y "Los Episodios Nacionales en el aprendizaje de la Historia". Es colaboradora del Centenario Galdós 2020.
} 
su educación, típica de un joven de la burguesía liberal de su época, que privilegiaba el estudio de las literaturas clásicas; de las tertulias y debates que frecuentaba en el Ateneo; de alguno de sus profesores de la Universidad, como Adolfo Alfredo Camús (profesor de latín) que influyó mucho en su ánimo y en su pensamiento; y de lo que vio y escuchó en el Congreso: el duelo oratorio entre los neos y los liberales sobre la idea de nación española, en el cual se oponían las dos imágenes contradictorias de España:

la de los ultramontanos, cifrada en un catolicismo de Estado [...] y la de los liberales, exaltada magníficamente por Castelar, quien [...] desarrollaba las grandiosas perspectivas abiertas por Hegel y los hermosos ensueños de tolerancia de Lersing, hermanando la idea de patria con la idea de progreso y de universalidad (Blanquat, 1977: 44)

Juana Sánchez-Gey (1990: 549) se atreve a aventurar unos rasgos específicos del humanismo:

a) El hombre, como individuo, es el centro y fundamento del ideal político-social-religioso.

b) El humanismo propone soluciones en las que quedan siempre a salvo la dignidad humana y la comprensión de su limitada condición.

c) Al mismo tiempo, tiene en cuenta los condicionamientos históricos interesándose de este modo por la razón histórica como configuradora de un pueblo.

$Y$ en este contexto cultural encuadra la personalidad de nuestro autor, puesto que asumiendo su realismo y minuciosidad por describir hasta el detalle tanto la personalidad psicológica de sus criaturas como el aspecto histórico y social de su época, asegura que:

este rico realismo galdosiano es consecuencia de su profundo humanismo que le lleva a crear personajes de una emoción sobrecogedora. Esta emoción sugiere al lector tal mundo de posibilidades y de matices, que penetran con nitidez en la vivencia siempre rica del tema y del problema del hombre (libidem: 550)

Pero, además, Galdós participa en otras corrientes filosóficas de su época, como el positivismo y el krausismo. Con respecto al positivismo, cabe decir que resulta difícil admitir que el realismo galdosiano haya sido consecuencia de este, pero que Galdós sí lo conoció y que aparece en muchas de sus obras. Por ejemplo, se puede observar en el personaje del ingeniero Pepe Rey de Doña Perfecta, al que describe como hombre de elevadas ideas y de inmenso amor a la Ciencia, y ciencia es sinónimo de gusto por lo empírico e incluso por el utilitarismo. Pero Clarín matiza el 
positivismo de su amigo y califica su filosofía no de positivista, pero sí de positiva, en el sentido de referirse a sus elementos éticos, políticos y físicos principalmente. Y añade que "la especulación por la especulación, el ensueño poético filosófico, no son de su gusto; la ciencia la quiere Galdós para algo práctico; el interés de la filosofía está en su aplicación a la conducta de los hombres" (Clarín, 1889).

Por lo que se refiere al krausismo, ya en sus novelas de tesis -Doña Perfecta (1876), Gloria (1876-1877), Marianela (1878) y La familia de León Roch (1878) - vemos cómo Galdós toma partido por el ideario de este movimiento encabezado por el filósofo Juan Sanz del Río (1814-1869), quien entre 1854 y 1868 se encargó de formar, desde su cátedra en la Universidad de Madrid, a toda una élite intelectual entre la que se contaban figuras tan destacadas como Gumersindo de Azcárate, Francisco Giner de los Ríos, Fernando de Castro y Nicolás Salmerón. Como señala Yolanda Arencibia:

Krausistas son los mensajes de fondo de estas novelas sociales lla insistencia en pro de la educación, por ejemplo) y posibles krausistas son sus protagonistas: el Pepe Rey de Doña Perfecta, el Buenaventura Lantigua de Gloria y el León Roch de la novela de su nombre [...] El único hombre de ciencia que triunfa en estas novelas es Teodoro Golfín, de Marianela, pero es un hombre de acción, un ser práctico que actúa con lógica, aunque Galdós le haga reconocer el inexorable humano que se le impone (Arencibia, 2020: 171)

El pensamiento de Sanz del Río procedía de una interpretación libre y muy personal de la filosofía del alemán Karl Christian Friedrich Krause (1871-1832) y se caracterizaba por el intento de conciliar los dogmas de la fe con los dictados de la razón. De acuerdo con esa premisa, los krausistas rechazaron las supersticiones y defendieron el cultivo de una firme actitud ética basada en los preceptos cristianos. Por otra parte, su hondo compromiso con los problemas sociales les indujo a denunciar sin tregua las deficiencias de las instituciones públicas y de la vida política española. A la hora de proponer estrategias para la regeneración del país, los krausistas confiaron un papel decisivo al desarrollo científico y a la educación, en la que vieron una forma de erradicar las supersticiones y las lacras morales y de infundirle al individuo la luz de la razón. Por eso proclamaron la necesidad de una enseñanza moderna y sin prejuicios, y por eso muchos de ellos se consagraron a las tareas educativas con una intensa dedicación. Esos afanes pedagógicos culminaron en 1876 con la fundación de la Institución Libre de Enseñanza en la que los krausistas se propusieron formar en sus principios éticos y sociales a los jóvenes que algún día habrían de gobernar España. Dado su interés por los problemas morales y políticos del país, el krausismo se convirtió muy pronto en toda una actitud ante la vida guiada por el amor a la razón, la ciencia, la verdad y el trabajo. Galdós trabó contacto con las ideas krausistas muy 
poco después de su llegada a Madrid y a través de tres fuentes distintas: las clases que recibió en la universidad del profesor Fernando de Castro, que era discípulo de Sanz del Río, su asistencia asidua al Ateneo, donde el krausismo era la ideología dominante, y la lectura de dos obras capitales en tal corriente intelectual: el ldeal de la humanidad para la vida de Krause, en la adaptación que Sanz del Río había redactado en 1860, y la Minuta de un testamento, de Gumersindo de Azcárate, publicada en 1876.

No resulta extraño, por to tanto, que las ideas del krausismo emerjan de continuo en las primeras novelas de Galdós, que defienden las libertades individuales y denuncian la intransigencia de la España tradicional. En varios casos, esas obras están protagonizadas por un personaje que abandera los ideales progresistas y que no consigue llevarlos a la práctica por culpa del inmovilismo de quienes profesan los principios de la vieja España. Su fracaso, sin embargo, no cuestiona la validez de unas ideas en las que Galdós creía con firmeza, tales como la necesidad de limitar el poder de la Iglesia y de abolir todo fanatismo en las prácticas religiosas, - en la consideración de la ciencia y la educación como medios insustituibles para modernizar y regenerar la sociedad española.

2.- IMPORTANCIA DE LA SOCIEDAD Y LA HISTORIA EN LA LITERATURA GALDOSIANA

Galdós plasmó en sus obras la idea de justicia y regeneración social. Dio cuenta a través de ellas de un cambio de época y consiguió hacerlo por medio de un estilo, de un impulso de representación realista que va evolucionando de forma permanente. Desde el punto de vista político vemos también esta evolución: crisis de fin de siglo, regeneracionismo, militancia republicana (la Unión Republicana, primero; la Conjunción Republicana Socialista, después; y finalmente, el Partido Reformista). En el conjunto de su obra (crónicas parlamentarias, actividad periodística, Episodios Nacionales, novelas, teatro) se puede observar un afán por explicar y comprender la historia de España, el desarrollo de la España contemporánea desde la epopeya que él entendía que partía de la guerra de la Independencia hasta llegar a ese proceso de construcción de la España moderna. Como autor, como historiador, fue construyendo narrativamente la España del siglo XX centrando su interés en la clase media y en lo que él llamaba el pueblo español, denunciando el papel que la religión ejercía sobre estos y ofreciendo distintas soluciones a los desajustes sociales que observaba a su alrededor.

Al llegar a Madrid y después de abandonar la carrera de Derecho, Galdós se dedica al periodismo a la vez que vive, como observador, la historia de España. En su dedicación a esta actividad se encuentra uno de los rasgos más significativos de su futura obra. Sus trabajos periodísticos 
empezarán a publicarse en la capital de España en 1865 en La Nación. Pronto estallan en España acontecimientos brutales y decisivos (1866) que marcarán un profundo hito en su vida: acontecimientos diversos del crack y de la crisis económica de ese año, "la noche de San Daniel, "el cuartel de San Gil", etc., precursores de la futura revolución de 1868. Va posteriormente a París, y de regreso de dicho viaje asiste al inicio de la crucial trayectoria de la revolución de octubre, tan magistralmente evocada en sus Episodios Nacionales. En medio de la marea que sigue al movimiento septembrino, se convertirá en el cronista de las sesiones de las Cortes Constituyentes para el periódico Las Cortes. En 1870 publica su primera novela, La Fontana de Oro, perteneciente al género histórico. En esta época, en medio del trasiego formidable que convulsiona a toda España, empieza a interesarse profundamente por los hechos históricos más cercanos, especialmente por los acontecimientos de la Guerra de la Independencia, hasta entonces olvidados por la mayoría de escritores e historiadores hispanos. Un interés que irá in crescendo a medida que pasará el tiempo. En 1872 comienza Galdós la primera serie de novelas históricas de los Episodios Nacionales, concluida en 1875 -diez novelas que representan otros tantos "episodios" de ese período histórico-épico que va desde Trafalgar al final de la Guerra de la Independencia-. Esta colección de diez volúmenes le define como fecundo escritor de gran talla y capacidad, con potencia suficiente para "pintar" un monumental retablo de la contemporánea historia española, en la que son protagonistas todos los miembros de la sociedad española decimonónica y que

supone ya un serio intento por despejar incógnitas aún cercanas, por llegar al fondo de cuestiones capitales y por desentrañar las diversas y complicadas motivaciones que mueven a una compleja sociedad en Iucha (Antoni Jutglar, 2012: 245)

Escribe después otras novelas, Doña Perfecta (1876), Gloria (1876-1877), Marianela (1878), La familia de León Roch (1878), novelas sociales que cierran la "primera época" del autor Galdós. Como vemos, la influencia del krausismo de Giner de los Ríos es clara y manifiesta; la preocupación por la España ahogada por el mezquino y represivo sistema de la Restauración canovista le conducía hacia aquel camino complicado en que una de las dos Españas había de desengañarle. En tal tesitura, lo histórico sigue a la zaga en Galdós en la tarea por describir la realidad social. Y así, entre 1875-1879 da a la imprenta otros diez volúmenes más de la segunda serie de los Episodios Nacionales. El período que historia ahora es el que va desde la Guerra de la Independencia hasta la restauración absolutista de Fernando VII.

A partir de 1880, Galdós se dedicó a retratar en sus obras la vida social tal y como era para que el lector la juzgara por sí mismo. En consonancia con los postulados del realismo, decidió documentarse a conciencia 
antes de escribir cada libro y en muchos casos recorrió cuaderno en mano las calles de Madrid buscando su inspiración en la vida cotidiana. Remedando a Balzac, se propuso describir la comedia humana de la sociedad española, y en particular los triunfos y fracasos de la clase media. En algunas de sus obras se hizo patente el influjo del naturalismo, la teoría del francés Émile Zola, quien defendía que la conducta del individuo está determinada por su fisiología, el ambiente que lo rodea y las leyes de la herencia. En el ámbito literario, Zola afirmó que el escritor tenía que adoptar ante la realidad la misma actitud objetiva y rigurosa ante la naturaleza y que la novela debía retratar la vida cotidiana en todos sus detalles, sin ocultar lo desagradable y lo sórdido ni eludir asuntos tan espinosos como el incesto, el adulterio o la prostifución. Estas ideas atrajeron a Galdós, que siempre se había mostrado convencido de que el medio determina el carácter del individuo y que ya había demostrado en sus primeras novelas sus facultades para describir ciertos episodios con aséptico rigor de un periodista científico. Sin embargo, fue en La desheredada (1881) donde se hizo más evidente su comunión con las ideas literarias de Zola, pues la novela retrata la vida de los suburbios de Madrid con la crudeza propia del naturalismo y muestra el peso de la herencia sobre el individuo al relatar la historia de una mujer que sufre delirios de grandeza porque en su familia ha habido varios casos de locura. Isidora Rufete, la protagonista de esta obra, transita todos los espacios madrileños de esa época, con sus zonas bien diferenciadas: el Madrid aristócrata y de las clases acomodadas, el Madrid sur de las aceras estrechas e incluso el de las afueras, de los suburbios y del hampa. Cada estamento se muestra en su paisaje, que aún se está definiendo; como se están redefiniendo las clases sociales que conocen los altibajos de negociantes que se hacen ricos y de aristócratas sin fortuna. La deuda con el naturalismo es también evidente en otras novelas de Galdós, como Tormento (1884), La de Bringas (1884) o Lo prohibido (1885). Con todo, Galdós nunca se sometió de modo servil a los dictados del naturalismo, y más de una vez los incumplió para aumentar el interés de los personajes y las situaciones narrativas de sus novelas. Pasada la fiebre del naturalismo, Galdós alcanzó un magisterio completo en el arte de novelar con Fortunata y Jacinta (1886-1887), donde traza un extenso cuadro de la vida de Madrid a partir de la historia de dos mujeres enamoradas del mismo hombre. La novela maneja con soltura a más de mil quinientos personajes, imita con precisión todos los estratos del lenguaje coloquial y erige espacios ficticios que resultan tan sólidos y creíbles como si pertenecieran al mundo real. Sin embargo, ninguna obra de Galdós es un mero ejercicio de virtuosismo técnico, ya que en todas ellas alienta un hondo sentido moral. Así sucede en Miau (1888), una novela que no solo denuncia con ironía la crueldad de la burocracia, sino que deja entrever los resortes de una sociedad inmoral y corrupta en la que apenas se practica la caridad. Convencido de que ninguna virtud resultaba más urgente que esa, Galdós convirtió la misericordia en un ideal y expresó su admiración por todos aquellos que se esforzaban en 
paliar la miseria de los otros sin esperar nada a cambio. Con tal generosidad obran la criada Benina en Misericordia (1897) y el clérigo que da nombre a Nazarín (1895).

Sin abdicar de su rigor ético ni de su voluntad de denuncia, las últimas novelas de Galdós abandonaron la senda del realismo y recurrieron al mito y a la alegoría. En los primeros años del siglo XX, el escritor expresó con firmeza su pesar por la situación política de España, que había perdido sus últimas colonias de ultramar en 1898 y se mostraba incapaz de atajar sus numerosos problemas internos. Por eso sus novelas El caballero encantado (1909) y La razón de la sinrazón (1915) vuelven a proclamar, aunque ahora con evidente talante utópico, la necesidad de que el país emprenda una urgente regeneración moral y política por medio del cultivo de la ciencia, la instrucción del pueblo llano y la justicia social.

Entre 1898 y 1912, Benito Pérez Galdós continúa publicando la tercera, cuarta y quinta series de los Episodios Nacionales, quedando esta última incompleta, ya que cuenta solo con seis novelas en lugar de las diez habituales. Había cerrado la segunda declarando la definitiva conclusión de los Episodios por cercanía cronológica con los hechos históricos, pero tras el lapsus temporal ya indicado acomete la reanudación del proyecto explicando la continuación del ciclo como respuesta a la llamada de la "opinión", y al consejo de sus amigos. Hoy sabemos que otras consideraciones pesaron en tal determinación: razones de índole económica y, también, razones de índole personal, consecuencia de los efectos del transcurrir histórico que agudizan su necesidad de reexaminar el pasado para extraer de él enseñanzas aplicables al presente. La redacción de las series continúa hasta Cánovas, sexto título de la quinta serie, que cierra definitiva y prematuramente el ciclo. En la interrupción de la serie debieron de pesar varios factores. Además de problemas de salud del autor y cierto pesimismo derivado de problemas económicos y de desilusiones o tensiones personales, fue esta interrupción expresión literaria de la frustración del autor ante la etapa histórica que había de novelizar.

Cabe recordar que cuando ya era muy mayor, Benito Pérez Galdós preparó una versión de sus Episodios dedicada a los niños. El criterio seguido para la adaptación fue el de destacar especialmente aquellos hechos en los que brillan el heroísmo de la resistencia patriótica y la nobleza de los ideales que la alimentaron. Sin apartarse un ápice de la verdad histórica y la objetividad, el autor plasmó narraciones dramáticas, vibrantes, cálidas, plenas de vida y colorido, que atrapan al lector y mantienen su interés como la más apasionante novela de ficción. De este modo publicó los Episodios Nacionales para uso de los niños: siete relatos amenos y atractivos, en los que enseñarles qué puede ser eso de "patria" 
y hasta dónde puede llegar el amor a ella. Estos Episodios son: Trafalgar, Madrid, 2 de mayo, Bailén, Zaragoza, Gerona, Cádiz y Arapiles.

Galdós no solo fue un maestro de la novela, sino también un fértil dramaturgo. El autor volvió al teatro en la última década del siglo XIX y retomó así una carrera frustrada en su juventud por la indiferencia con que los empresarios teatrales habían acogido sus obras. Al principio, Galdós se limitó a adaptar para la escena algunas de sus propias novelas, como Realidad (1892) o Gerona (1893), pero muy pronto empezó a escribir directamente para el teatro, lo que le permitió transmitir sus ideas políticas y morales a un público mucho más amplio que el de la novela. El teatro de Galdós utilizó las intensas pasiones del melodrama para reflejar los conflictos fundamentales de la sociedad decimonónica. Por lo general, tos personajes de sus obras se dividen en dos facciones: los que creen en una España basada en la libertad individual, el amor al trabajo, el reparto de la riqueza y el espíritu caritativo -Celia en los infiernos (1913)-, y los que desdeñan cualquier cambio social y practican la intolerancia y la hipocresía. En este último bando sitúa Galdós a la Iglesia y a la aristocracia, por considerarlas culpables del retraso social del país. El ataque a los prejuicios de la nobleza presente en obras como El abuelo (1904) y el anticlericalismo de piezas como Casandra (1909) provocaron la furia de los conservadores. Esta circunstancia contribuyó de forma decisiva a la enorme trascendencia social de su teatro, bien demostrada años antes en el estreno de Electra (1901), a raíz del cual Galdós fue invitado a entrar en política de nuevo. El escritor ya había sido diputado por el partido liberal entre 1886 y 1891, aunque nunca había participado de forma activa en la vida parlamentaria. En 1906 ingresó en el partido republicano, por el que sería elegido diputado en tres ocasiones. Sin embargo, el tiempo le demostró que la política española era pura retórica y, decepcionado, decidió abandonarla. De hecho, el autor nunca confió demasiado en que el poder del Estado pudiera cambiar la realidad del país, y sostenía la convicción krausista de que la regeneración de España solo podría llevarse a cabo a partir de la mejora individual de cada uno de sus ciudadanos.

Es Celia en los infiernos (1913) una muestra perfecta del Galdós más combativo de los últimos años. En ella plantea una serie de temas que le vienen preocupando desde hace tiempo, pero que se van radicalizando y le van acercando a las ideas socialistas de Pablo Iglesias: la solución a la miseria que sufren los más pobres es el equilibrio social -de ahí que Celia se proponga repartir su riqueza entre los habitantes del infierno-; el matrimonio como unión de clases sociales distintas por medio del amor de sus componentes -que resulta imposible en esta comedia-; el papel reservado a la mujer que Celia se esfuerza por cambiar ("a las señoras se las debe dejar encastilladas en su fe", dice don Alejandro); la justicia y no la caridad para resolver los problemas de los desheredados; la concordia entre las clases altas y las humildes; los derechos laborales de los 
trabajadores...(http://litenatura.blogspot.com/2020/11/celia-en-losinfiernos-de-benito-perez.html).

La labor literaria de Pérez Galdós fue ingente, ya que se compone de cuarenta y seis Episodios Nacionales, treinta y una novelas, veintitrés obras de teatro y veintitrés cuentos, además de infinidad de artículos y prólogos y un libro de memorias: Memorias de un desmemoriado. A la larga, tan intensa dedicación profesional acabó por dañarle la vista, por lo que desde 1910 Galdós se vio obligado a dictar sus obras a un amanuense. En sus últimos años, el escritor sumó a la desgracia de una ceguera casi completa sus acuciantes problemas económicos, ya que, aunque la literatura le había proporcionado mucho dinero, llevaba un tren de vida demasiado lujoso.

Para compensar sus méritos literarios y aliviar sus apuros económicos, algunos amigos decidieron presentar a Galdós como candidato al Premio Nobel de Literatura pero los detractores del escritor batallaron con ardor en su contra, de modo que las razones políticas acabaron por arrebatarle toda esperanza de obtener aquel galardón que tanto merecía. La misma Academia de la Lengua que había elegido a Galdós entre sus miembros en 1889 se negó a apoyar su candidatura por motivos ideológicos. Galdós murió tras largas semanas de agonía el 4 de enero de 1920.

\section{3.- HUELLA DE GALDÓS EN LOS NOVELISTAS SOCIALES DE NUESTRO TIEMPO}

En este apartado entenderemos la novela social como la novela que estudia los efectos de las condiciones sociales y económicas en un tiempo y lugar determinados sobre los hombres y sus conductas, y lo iniciaremos con Juan Marsé quien en una entrevista confiesa su deuda con Galdós: "Yo me siento más próximo de los despreciados garbanceros, que serían Baroja y Galdós, y me gustaría aproximarme a Stevenson y a Dickens, y a Nobokov" (ABC, viernes 21-V-1993). Y que pone estas palabras en boca del autor protagonista de su novela Esa puta tan distinguida en una entrevista que le hacen al comienzo de la obra con las que declara su anticlericalismo: "Los únicos clérigos que respeto son el padre Pietro de Roma, città aperta, de Rosellini, el Nazarín de Galdós/Buñuel, el padre Brown de Chesterton y el furioso y zarrapastroso cura irlandés de La hija de Ryan, de David Lean" (Marsé: 2016, 9-10).

Gustavo Martín Garzo (El País, jueves 23-IV-2009) señala que son muchas las cosas que unen a Juan Marsé y a Benito Pérez Galdós: su visión pesimista del ser humano, su capacidad para situarse en el lugar de la derrota y el fracaso de los ideales, y el que sus novelas sean algo así como un gran almacén de las emociones humanas; pero, sobre todo, la facilidad con que sus personajes se desplazan del mundo real al mundo 
de los sueños. Es esta cualidad la que les hace tan sensibles a lo amoroso, que siempre tiene que ver con la ensoñación. Y pone como ejemplo a los personajes más inolvidables de Marsé: el Java de Si te dicen que caí, el Pijoaparte de Últimas tardes con Teresa, la Susanita y Daniel de El embrujo de Shanghai, no dejan de fantasear acerca de los demás o de sí mismos, ni de confundir el mundo real con el de sus sueños. Sobreviven contándose historias, pero la ficción no es sólo para ellos una forma de evadirse de un mundo en el que predominan la violencia y la represión, sino la posibilidad de salvar las verdades más hondas de lo que son. Los personajes que pueblan el mundo de Marsé, intentan transformar el degradado paisaje en que viven en un paisaje moral. Tal vez por eso, los dos pilares básicos de este mundo son el regreso del héroe y la reivindicación del amor y de la amistad.

En las novelas de Marsé el protagonista siempre busca algo que perdió y quiere recuperar, algo que tiene que ver con ese viejo idealismo que se opone a la penosa realidad del presente. Los protagonistas son hombres cansados o muchachos confusos que viven entre la inmundicia, o pobres mujeres a las que la vida ha condenado a la soledad y la degradación, pero en los que aún late esa antigua capacidad del corazón humano para conmoverse ante la luz y el brillo del mundo. Es esta búsqueda de los lugares encantados del pasado la que les hace vivir.

Nuestra experiencia lectora nos lleva a estar totalmente de acuerdo con Gustavo Garzo, las reseñas que de las obras de Marsé hemos hecho en nuestro blog así lo atestiguan.

Esa puta tan distinguida: Novela de calidad como no podía ser menos, ya que está escrita por Juan Marsé. En esta ocasión el argumento trata de un escritor que se dispone a escribir un guion cinematográfico sobre un crimen cometido en 1949: el de una prostituta en la cabina de proyección de un cine de barrio. Para ello cuenta con el testimonio del asesino confeso, que recuerda lo sucedido, pero no el motivo que le llevó a cometerlo. La razón de este olvido está en un tratamiento empleado por un psiquiatra adepto al régimen, Tejero-Cámara, para hacer olvidar partes de la vida de una persona y borrar los recuerdos de hechos cometidos en el pasado. El psiquiatra en cuestión existió en la realidad Vallejo-Nájera-, que adquirió parte de su fama y prestigio experimentando esta técnica en presos durante la posguerra española, a fin de eliminar en ellos lo que él llamaba el "gen rojo". La memoria, por tanto, se convierte en la verdadera protagonista de la historia y ella es esa puta tan distinguida a que hace referencia el título, que también juega con la profesión de la mujer asesinada, Carol. Son destacables el humor y la ironía presentes a lo largo del relato, especialmente en el escritor que debe escribir el guion: en las respuestas que da en la entrevista con que comienza el libro; en sus reflexiones sobre lo que debe y no debe escribir; en sus diálogos con el director de la película, con los 
productores y con una actriz aspirante a uno de los papeles; en sus conversaciones con Feli, su asistenta, etc. El cine también juega un papel muy importante como suele ocurrir en las novelas de Marsé, no sólo porque el asesino es el operador y el crimen tiene lugar durante su trabajo, mientras el público contempla una reposición de Gilda, sino por la afición que el escritor-narrador tiene por el séptimo arte, por las adivinanzas que sobre películas y actores le propone continuamente Feli, por la presencia de unos muchachos en el cine dispuestos a colarse para ver al mito erótico de la época o por cómo explica a los lectores el proceso de proyección de películas de reestreno en los cines de barrio.

A pesar de que se nota la firma de Marsé -autor sublime de novelas de perdedores- en la amargura de Carol, en la vida de Fermín Sicart, de Liberto Augé y de Braulio Laso Badía, echo en falta la emoción y la ternura de otras novelas suyas, como Un día volveré o Caligrafía de los sueños. Alguna escena de esta última aparece en esta novela como el libro que el narrador debería escribir en lugar del guion cinematográfico que finalmente escribe y que será totalmente transformado por razones puramente comerciales.

(https://litenatura.blogspot.com/2016/06/esa-puta-tan-distinguida-dejuan-marse.html).

Ronda del Guinardó: Se trata de un relato de perdedores que tiene como escenario una zona muy concreta de Barcelona: el Guinardó. En él, un inspector enfermo e irascible acompaña a una huérfana a reconocer el cadáver de un hombre que podría ser el que la violó dos años atrás. Temas como la explotación, la prostitución, la religión, la caridad, la marginalidad, tienen cabida en esta corta pero intensa novela.

(https://litenatura.blogspot.com/2009/12/ronda-del-guinardo.html).

Un día volveré: Magnífica novela de Juan Marsé. Todo su mundo literario está presente en ella: los perdedores, el cine, Barcelona, la gente del barrio, la posguerra, la delincuencia, la política, los adolescentes, las "aventis"... Todo ello rodeado de una atmósfera de misterio y melancolía que logra sumir al lector en un tiempo y en unos acontecimientos pasados que debe reconstruir a través del testimonio de los personajes. Esto es lo que ocurre con la historia del protagonista, Jan Julibert Mon, que vuelve a casa tras pasar unos años en la cárcel. Todo el barrio está pendiente de cómo va a retomar su vida, si va a ejercer una suerte de venganza contra los que le enviaron a prisión. Su sobrino Néstor, el narrador que se supone que es uno de los integrantes de la pandilla de éste, el viejo Suau... Todos observan sus movimientos intentando averiguarlo, mientras él no ofrece ninguna pista con su actitud, ya que lleva una vida ordenada, se busca un trabajo y se aleja de sus antiguos compinches. Néstor, que tenía una imagen idealizada de su tío no da crédito de lo que ve y poco a poco la desilusión le invade, porque las expectativas que tenía en torno a él no se cumplen. Los personajes están trazados con precisión y sin concesiones destacando, además del protagonista, su 
cuñada Balbina, el juez Luis Klein y Néstor, un joven aficionado al boxeo y a meterse en problemas para evadirse de la triste realidad que le rodea. Novela magistral de principio a fin, que deja muchos interrogantes al lector para que este intente responderlos.

(https://litenatura.blogspot.com/2019/03/un-dia-volvere-de-juanmarse.html).

Últimas tardes con Teresa: Todo en esta novela es magistral: el dominio del lenguaje que realiza Marsé, la ironía de sus reflexiones, la crítica social y política de la época y, sobre todo, sus personajes. Manolo, "el Pijoaparte", sobresale entre todos, seguido de Teresa, Maruja, Hortensia y el Cardenal. El protagonista -un ladrón de motocicletas, tironero ocasional, ligón empedernido- quiere ascender de estatus a través de Teresa -una niña rica de la burguesía catalana, universitaria con ideas revolucionarias-, pero como suele ocurrir en las novelas de Juan Marsé se convierte en un perdedor, en este caso víctima de la traición de Hortensia. La descripción de los diferentes ambientes en los que se mueven ambos (el Monte Carmelo, la Vía Augusta, la villa de Blanes y la universidad de Barcelona con sus revueltas estudiantiles) nos hacen volver a una época, finales de los 50, en la que la política jugó un papel fundamental para algunos que, como en el caso de Teresa, querían cambiar unas cosas, pero sin renunciar a otras. Con esta obra Marsé consiguió enfadar a unos -franquistas- y a otros -progres pseudocomunistas-, pero lo más importante: logró enamorar a una pléyade de lectores que siguen emocionándose con la historia que cuenta. Tanto el principio como el final de la obra son sublimes, ya que en ellos se ve el contraste entre los sueños de Manolo y la realidad que le rodea. Una nota de humor: el propio Marsé aparece como personaje secundario pellizcando las nalgas de las muchachas en un baile dominical de obreros.

(https://litenatura.blogspot.com/2016/08/ultimas-tardes-con-teresa-dejuan-marse_2.html).

Caligrafía de los sueños: Trata de un adolescente-Ringo-que nos cuenta cosas de su vida y de los que le rodean. El final es sorprendente: nada es lo que parece. Transmite al lector un sentimiento de fracaso, común al resto de sus novelas. Los sueños nunca se pueden materializar, siempre pasa algo que lo impide. La realidad hace su aparición desbaratándolo todo.

(https://litenatura.blogspot.com/201 1/03/caligrafia-de-los-suenos.html).

Germán Gullón, uno de los mayores expertos en la obra galdosiana, asegura (Diario de Córdoba, sábado 4-I-2020) que en España "no ha habido una transición cultural, como sí la hubo política, y Galdós fue entrando a través de autores individuales y no de una forma general". Y que, aun así, unos cuantos escritores se declaran galdosianos o practican 
una manera de contar sus historias que evoca a la del autor de Fortunata y Jacinta. Sostiene que la huella del escritor canario en los autores actuales es "muy poquita" y apunta: "No creo que haya ninguno del que se pueda decir que es galdosiano total".

Este crítico literario pone nombre al autor de la literatura actual más galdosiano: Rafael Chirbes. El escritor valenciano llegó a reconocer que la relectura de la cuarta serie de los Episodios Nacionales le acompañó mientras escribía En la orilla. Gullón asegura que "como novelista, Rafael Chirbes tenía algo que era lo mismo que quería Galdós y era contar una historia bien contada, y eso iba en contra de la tendencia". La larga marcha y La caída de Madrid son dos novelas de Chirbes muy galdosianas en las que el novelista va por un camino paralelo al que sigue la novela considerada en España como más literaria, aquella que cultivaba Juan Benet. En resumen, "una novela literaria frente a otra que quería contar una historia bien contada", explica Gullón.

Y bien contada está la historia de La orilla (hittps://litenatura.blogspot.com/2015/08/en-la-orilla-de-rafael-

chirbes.html), una novela que atrapa la atención del lector no solo por los temas que trata, sino por la manera que tiene de contar la historia con la que se ocupa de ellos. El principal de todos es la crisis, el fin de la época del ladrillo o de la burbuja inmobiliaria; pero la novela no se reduce a esto, es mucho más: la desesperanza que provoca el ser humano cargado de miserias -egoísmo, interés, explotación, engaño, afán por presumir de las riquezas, falsa humildad, cobardía, envidia, celos, etc.-, las ilusiones, la inercia o el dejarse llevar en la vida, la necesidad de trepar a costa de lo que sea, los favores, la maledicencia, la inmigración, el paro, la familia, la amistad, la enfermedad, el desengaño, la vejez... Y como telón de fondo el marjal, el pantano, testigo de las sucesivas etapas de la historia de ese entorno donde se desenvuelven los personajes. El autor demuestra maestría en el dominio del lenguaje y en el uso de las técnicas narrativas, ya que no se conforma con el uso de la tercera persona de un narrador omnisciente, sino que recurre a los monólogos (utilizando en ellos la primera y la segunda persona) y a los diálogos; a las anticipaciones y retrospecciones; y realiza unas descripciones minuciosas que revelan una asombrosa capacidad de observación de la realidad que le rodea, a las que añade un peculiar toque de ironía. La novela se divide en tres partes: El hallazgo, Localización de exteriores y Éxođo. Su protagonista es Esteban, un carpintero de setenta años que tiene que cerrar su negocio por una serie de razones que él mismo explica, que cuenta cómo ha llegado hasta ahí: solo, soltero, cuidando a su padre, un enfermo terminal de noventa años, viviendo en el pueblo una vida aburrida de la que no ha querido o podido escapar. Varios personajes aparecen en el relato, como Francisco, Liliana, el tío Ramón, Pedrós, Leonor, Justino, Álvaro, Julio, Ahmed, etc. 
Además de a Almudena Grandes, Germán Gullón incorpora a Andrés Trapiello y Muñoz Molina en el censo de autores en los que se puede hurgar cierta huella galdosiana, aunque insiste en que ninguno es "galdosiano total". El escritor grancanario Santiago Gil publicó en 2019 El gran amor de Galdós, una novela donde cuenta un episodio de la vida del escritor, su primer amor con una prima suya cubana, María Josefa Washington Galdós Tate, conocida por Sisita. Esa novela, dice Gullón, es "la única que conozco realmente como galdosiana".

En una reciente entrevista, realizada con motivo de la publicación de su libro Galdós. Una biografía (https://www.revistadelibros.com/blogs/viajea-siracusa/cien-anos-sin-galdos-dialogo-con-yolanda-arencibia),

preguntada por los herederos, los narradores que han forjado su estilo inspirándose en los hallazgos de Benito Pérez Galdós, Yolanda Arencibia responde lo siguiente:

Muchos novelistas del ayer inmediato y de hoy se han declarado entusiastas de su obra y herederos de ella de algún modo; y en otros puede percibirse esa huella con declaración o sin ella. El asunto precisaría un análisis profundo. Aventuraré algunos nombres, a sabiendas de que me faltan otros, y de que la presencia de Galdós en los citados se manifiesta de forma muy diferente. Pensemos en Buñuel, por ejemplo, que declaró no tener otra fuente literaria que Galdós, que basó en novelas galdosianas creaciones propias geniales, y que algunas de sus iluminaciones tuvieron en don Benito un precedente; o en García Lorca, Aleixandre, Cernuda, Zambrano o Max Aub, a quienes inspiró escritos de distinta naturaleza; o en J. A. Zunzunegui y, en general, en los narradores realistas de los sesenta-setenta del siglo XX. Pensemos en la cercanía galdosiana de Manuel Longares o Rafael Chirbes; en el mundo de Rafael Reig; o en el realismo de Emilio González Déniz; o en Belén Gopegui, Carolina Molina, Isaac Rosa; en Santiago Gil ...; o en Almudena Grandes, la novelista más fiel al maestro...

Resulta curioso observar que no se limita a citar a novelistas, sino que incluye a cineastas como Buñuel y poetas como García Lorca, Aleixandre - Cernuda, que mostraron su rendida admiración por nuestro autor. Por supuesto, estamos de acuerdo con ella, aunque añadiríamos a Juan Marsé, Andrés Trapiello, Antonio Muñoz Molina, Elvira Lindo o a Care Santos. Estos cuatro últimos escritores, junto con Almudena Grandes y Manuel Longares, son entrevistados en un audiovisual dirigido por Arantxa Aguirre -Seis visiones actuales sobre Galdós- que forma parte de la exposición Benito Pérez Galdós. La verdad humana, que estuvo en la Biblioteca Nacional de Madrid y en la actualidad se encuentra en la Casa Museo Pérez Galdós de Las Palmas de Gran Canaria. Cada uno de ellos reconoce su deuda con Galdós, a la vez que defiende la vigencia de su legado. 
Así, Almudena Grandes se confiesa galdosiana no solo como lectora, sino también como escritora, al mismo tiempo que recuerda su proyecto de escritura de seis Episodios de una guerra interminable inspirados en los Episodios Nacionales de Galdós. En efecto, el día 3 de septiembre de 2010 llegó a las librerías la primera de las obras de esta sextalogía: Inés y la alegría, que abarca un período temporal de veinticinco años de la Historia de España, concretamente de 1939 a 1964. De esas seis hoy se han publicado cinco, la ya citada Inés y la alegría, El lector de Julio Verne, Las tres bodas de Manolita, Los pacientes del doctor García y La madre de Frankestein. Falta otra que ya tiene título: Mariano en el Bidasoa. Cada novela es independiente, pero varias comparten personajes. Todas terminan en 1964 y todas tienen un epílogo en 1977 o 1978. "Quería vincular las historias con el presente y enfrentar al lector actual con su pasado", dice su autora (El País, jueves 24-IV-2010). Coincide con Galdós en contar el cruce entre la historia inmortal y los cuerpos mortales, "construir una historia de ficción que encaja en el molde de un hecho real en el tiempo y en el espacio, un relato en el que los personajes reales de la Historia con mayúsculas interactúan con los de la historia con minúsculas" (Ibidem). Hemos leído las cinco novelas y en todas ellas destacamos la ingente labor de documentación que ha llevado a cabo su autora para poder escribirlas y el hecho de que en todas encontramos guiños y referencias a Galdós. He aquí las reseñas que elaboramos tras su lectura.

Inés y la alegría: Hay que reconocer el mérito de Almudena Grandes a la hora de escribir esta novela: la labor de documentación que ha realizado es magnífica. Ha contribuido con este relato a dar a conocer un capítulo de la historia de España desconocido para la inmensa mayoría de los españoles: la invasión del Valle de Arán llevada a cabo en 1944 por un grupo muy numeroso de exiliados que quedaron abandonados a su suerte y tuvieron que abandonar y volverse a Francia. Además, para los seguidores de Galdós este homenaje a su figura -escribir una suerte de Episodios Nacionales sobre una época oscura de la historia española, la posguerra y la dictadura- es, cuando menos, emocionante. Siempre ha confesado esta escritora su pasión por la obra de Benito Pérez Galdós y con esta obra cumple uno de sus sueños: utilizando la técnica galdosiana de mezclar hechos reales con otros ficticios pero verosímiles, consigue rendir su peculiar tributo al maestro. Sólo he encontrado algunos fallos en los episodios pertenecientes al mundo de la ficción, especialmente en lo que concierne a Inés, Galán y sus compañeros de fatigas: resultan poco creíbles, exagerados y tópicos. Aun así, consiguen atrapar la atención del lector de principio a fin.

Un detalle que me ha emocionado especialmente es el de las rosquillas, ya que en una de sus obras de teatro -La de San Quintín- Galdós las utiliza como símbolo de la mezcla de las distintas clases que conforman la 
sociedad española, si bien es cierto que la autora de Inés y la alegría hace uso de ellas en demasiadas ocasiones, resultando un tanto reiterativa.

(https://litenatura.blogspot.com/201 1/08/hay-que-reconocer-el-meritode-almudena.html).

El lector de Julio Verne: Se trata de la segunda entrega de la serie de Episodios de una Guerra Interminable que Almudena Grandes dedica a la guerra civil y a la posguerra española. Me ha gustado mucho más que la primera, Inés y la alegría, porque no es tan reiterativa como aquélla, su protagonista no es tan arrogante y los acontecimientos que narra están mejor estructurados. Además, la autora refleja perfectamente las dudas, las inquietudes, los miedos y el asombro de Nino ante la asfixiante atmósfera que le rodea en la Casa Cuartel de la Guardia Civil de Fuensanta de Martos, un pueblo de Jaén, donde vive. También es destacable el misterio y el mito que logra crear en torno a los hombres que habitan en el monte; sus mujeres, que viven en el pueblo; y aquellos que logran escapar. Muy bien trazados los personajes: desde el protagonista -un niño de nueve años- a Pepe el Portugués, pasando por los guardias civiles, sus familias, las Rubias, Doña Elena, etc. Impagable el homenaje a Galdós que Almudena Grandes hace en las páginas de este libro, cuya acción principal transcurre entre 1947 y 1949.

(https://litenatura.blogspot.com/2012/07/el-lector-de-julio-verne-dealmudena.html).

Las tres bodas de Manolita: Magnífica. Este es el calificativo que merece esta novela -el tercero de los Episodios de una Guerra Interminable- de Almudena Grandes por varios motivos: la ingente labor de documentación llevada a cabo por la autora, la agilidad de su prosa, la cantidad y variedad de personajes que aparecen y tramas que desarrolla, el continuo homenaje que realiza a la Literatura con mayúsculas (Galdós y sus Episodios Nacionales, La isla del tesoro, etc.), la sensibilidad que desprenden sus reflexiones, la descripción de ambientes, las claves históricas que desentraña, las técnicas empleadas fnarrador omnisciente, narrador protagonista, anticipaciones, diversidad de puntos de vista), la aparición de personajes de sus dos obras anteriores (Inés y la alegría y El lector de Julio Verne) y de su obra inmediatamente posterior que ya nos adelanta, Los pacientes del doctor García...Por todo ello y más es una novela de lectura imprescindible. Su argumento gira en torno a Manolita Perales, que ve cómo su vida y la de los suyos cambia a partir de 1939. Las más bajas pasiones del ser humano se desatan en la posguerra española y Almudena Grandes es capaz de lograr que el lector asista impotente a este desgraciado espectáculo: delación, tortura, asesinato, egoísmo, explotación de menores, ambición, injusticia, miedo, dolor, despotismo; aunque aporta un rayo de esperanza: solidaridad, esfuerzo, trabajo, paciencia, amistad, amor. 
(https://litenatura.blogspot.com/2014/07/las-tres-bodas-demanolita.html).

Los pacientes del doctor García: Cuarta entrega de los Episodios de una Guerra Interminable. Es quizá la obra más ambiciosa y complicada de las cuatro debido al número de personajes, tiempos y escenarios en los que se desarrolla. El argumento gira en torno a Guillermo García, un médico republicano que se ve envuelto en una operación de espionaje para descubrir y desmantelar una poderosa red que, durante los años 40, da refugio a criminales nazis en España y les ayuda a huir y a establecerse en Argentina en la más absoluta impunidad. Se trata de la "Red Stauffer", capitaneada por Clara Stauffer (una mujer que desempeña un papel muy destacado durante el franquismo fundando la Sección Femenina) que se dedica en cuerpo y alma a acoger a esos criminales y a evitar que caiga sobre ellos todo el peso de la ley proporcionándoles una nueva identidad, dándoles trabajo y facilitándoles a aquellos que así se lo pidan su establecimiento en Argentina, cuando no en España, todo ello bajo el auspicio de Franco y de Perón y la indiferencia e inoperancia de los aliados, en este caso, Inglaterra y Estados Unidos. Guillermo García se verá inmerso en este asunto que le es del todo ajeno por amistad y lealtad a su amigo Manuel Arroyo, diplomático durante la República. Ambos verán cómo sus vidas cambian, igual que sus identidades y profesiones, en aras del éxito de la República, a cuyo servicio trabajan para poner en evidencia a la facción ganadora de la guerra civil ante los organismos internacionales revelándoles el paradero de los asesinos de miles de judíos que disfrutan de su libertad bajo la protección de los regímenes fascistas español y argentino. Este esfuerzo resultará inútil porque les interesa más contar con la ayuda de Franco contra Stalin, que con los republicanos. La novela tiene como escenarios España, Suiza, Inglaterra, Rusia, Berlín, Argentina y por ella desfilan multitud de personajes reales (Negrín, Azcárate, Clara Stauffer...) y ficticios (Adrián Gallardo, Amparo, Experta, Rita, Simona, Meg, etc.) ante los que el lector debe estar muy atento para no perderse. Empieza durante la guerra civil y acaba con la dictadura argentina de Videla y compañía. La labor de documentación realizada por la autora es impresionante, no en vano ha tardado cuatro años en escribir esta obra. A pesar de tanta información histórica, el relato de los avatares de los personajes logra llegar al lector que se sigue emocionando con ellos. Grandes continúa incluyendo sus guiños a Galdós: el ejemplar de Bailén que Pepe Moya envía a Guillermo con información cifrada de gran trascendencia para el destino de Manuel; o la lectura de Trafalgar de Guillermo a su hijo durante la enfermedad de este. También emociona encontrarse con personajes de Episodios anteriores: Inés (de Inés y la alegría), Pepe "el Portugués" (de EI lector de Julio Verne) o Manolita Perales (de Las tres bodas de Manolita). (https://litenatura.blogspot.com/search? $\mathrm{q}=\mathrm{los}+$ pacientes+del+doctor+g arc\%C3\%ADa). 
La madre de Frankestein: Quinta entrega de los Episodios de una Guerra Interminable de la sextalogía proyectada por la autora. El subtítulo de esta obra es ya una declaración de intenciones: "Agonía y muerte de Aurora Rodríguez Carballeira en el apogeo de la España nacionalcatólica, Manicomio de mujeres de Ciempozvelos, Madrid, 19541956". En efecto, con una minuciosa labor de documentación detrás, el libro reconstruye esa época del franquismo en la que sitúa la historia que cuentan tres personajes: Germán, un psiquiatra exiliado que regresa de Suiza para poner en marcha un proyecto en el manicomio de mujeres de Ciempozuelos; María Castejón, una auxiliar de enfermería criada en esa institución porque es la nieta del jardinero; y Aurora Rodríguez Carballeira, interna de por vida en el citado establecimiento tras asesinar a su hija Hildegart. A través de los testimonios de estos personajes que rememoran sus respectivas vidas, el lector asiste a unos hechos que sucedieron en España (una guerra fratricida, la posterior represión, el poder ejercido por la Iglesia, la absoluta falta de libertad de la mujer, la diferencia de clases, el atraso, el progreso supeditado a la lucha de los egos, la miseria, el exilio, efc.) y se le insta a reflexionar sobre ellos. Como en los Episodios Nacionales de Galdós - a quien Almudena Grandes homenajea como acostumbra desde la primera a la última página-, personajes reales y ficticios se relacionan en el relato con total naturalidad; y para que quede constancia de ello, en la parte final del libro aclara quién es real y quién, pura invención. El conjunto resulta apasionante hasta el punto de que al lector se le hace difícil tomarse un respiro para proseguir y concluir su lectura. Al igual que en Episodios anteriores, la última parte se sitúa los inicios de la democracia y en ella se conoce cuál ha sido el devenir de los principales personajes. A mi juicio, este Episodio es uno de los más conseguidos de la serie, tanto por el tema como por la manera de desarrollarlo y conectarlo con temas de actualidad, de los que podría ser un ejemplo el de los niños robados, por la cantidad de personajes, la variedad de las historias que cuenta y los lugares en los que se desarrolla.

Hablaba antes del homenaje a Galdós que realiza la autora: en la dedicatoria aparece un fragmento del precioso poema de Luis Cernuda, "Díptico español" en el que se le menciona; en las páginas 265266 y 440, María Castejón recuerda las obras que ha leído de este autor y compara una parte de su peripecia vital con la de Fortunata; y en la página 557, Benito Pérez Galdós es nombrado al referirse a José María Esquerdo porque compartió lista electoral con él y con Pablo Iglesias por la coalición republicana socialista en 1910.

(https://itenatura.blogspot.com/2020/08/la-madre-de-fankesteinalmacena-grandes.html).

Pero no solo se observa la influencia del autor canario en este proyecto de Almudena Grandes: como ella misma reconoce, ha leído y releído a 
Galdós continuamente mientras escribía sus libros, por lo que asegura que habrá ecos de don Benito en prácticamente todo lo que ha escrito. De hecho, recuerda a un profesor de la Universidad Autónoma de Barcelona, Sergio Besser Ortí, que comparaba a la protagonista de Los aires difíciles (un apasionante relato de las vidas de dos personajes, vecinos en una Iujosa urbanización de un pueblo costero de Andalucía y una interesante reflexión sobre las relaciones familiares), Sara Gómez, con Isidora Rufete.

Grandes en su entrevista destaca, además, que los escritores del 27 -a su juicio los más brillantes-se fueron al exilio a amar a Galdós y pone como ejemplos a Luis Cernuda, cuyo poema "Díptico español" aparece en todos sus Episodios, en el que dice que sigue siendo español porque existe Galdós; a Luis Buñuel, que se fue a México a hacer películas basadas en novelas de Galdós; a Rafael Alberti y María Teresa León que cuando se establecieron en Argentina lo primero que hicieron fue publicar a Galdós; y a Max Aub, que escribió en México El laberinto mágico para contar la guerra civil siguiendo el modelo de los Episodios Nacionales.

Antonio Muñoz Molina en el mismo audiovisual se proclama galdosiano de nacimiento, de vocación y de pasión. Señala que, como lector, lleva leyendo a Pérez Galdós toda su vida y que, como escritor, hay muchas lecciones que para él es muy importante aprender de este autor, entre otras cosas la relación entre las vidas privadas y las circunstancias históricas, es decir, el reflejo de la atmósfera política y social en cada momento, no solo en los Episodios Nacionales sino en el conjunto de su obra. En cuanto a su obra más relacionada con Galdós destaca sin duda La noche de los tiempos, porque es una novela en la que intenta reconstruir un cierto período histórico con una doble intención: por una parte, crear personajes verdaderos de carne y hueso que viven en unas circunstancias históricas y por otra, mostrar un período histórico con una intención política, no arqueológica. Esa intención de imbricar vidas privadas en un avatar histórico está muy influida por Pérez Galdós. Señala que nuestra época contemporánea está muy marcada por los efectos de la crisis de 2008 y del gran colapso político que estamos viviendo internacionalmente, y que por ello necesitamos que nos cuenten literariamente los grandes debates políticos, sociales, de desigualdad, de emancipación, como hizo Galdós, no en panfletos. Y que eso es lo que él pretende hacer.

En nuestra lectura de La noche de los tiempos (https://litenatura.blogspot.com/201 1/07/la-noche-de-los-tiempos-deantonio.html) sacamos la conclusión de que consigue su propósito. Lo que en un principio parece la crónica de un adulterio se convierte en un magnífico relato ambientado en los momentos previos de la Guerra Civil española. A lo largo de novecientas cincuenta y ocho páginas, el autor hace gala de su prodigioso dominio de la prosa y nos sumerge en los lugares y personajes destacados del Madrid de la preguerra: la frustrada 
Ciudad Universitaria que el protagonista -arquitecto encargado de cristalizar el proyecto- no logra concluir, la Residencia de Estudiantes, Moreno Villa, Juan Negrín, Azaña, Bergamín, Alberti, Salinas, Lorca, Ortega y Gasset, Unamuno, la Sierra, etc. Poco a poco Madrid se va transformando en un infierno conforme avanzan las tropas insurrectas y el protagonista, Ignacio Abel, no da crédito a los trágicos cambios que acontecen. Puede más su amor por Judith Bieley -una profesora americana a la que conoce tras una conferencia- que su propia familia y que su país. Nos gusta mucho ta imparcialidad del autor, que no tiene inconveniente en mostrarnos el lado más cruel de ambos bandos contendientes: tanto los unos como los otros son capaces de cometer las más atroces acciones aprovechando la inestable situación de los primeros mómentos. Mal parados salen algunos personajes reales de nuestra cultura y de nuestra historia: Bergamín, Salinas y Alberti, especialmente, cada uno de ellos por diferentes motivos.

Andrés Trapiello, por su parte, señala que es muy difícil no sentirse galdosiano de la misma manera que es difícil no sentirse cervantino o barojiano, aunque "quizás sea más sencillo lo de Galdós" porque es un escritor que no está tan alejado de nosotros como Cervantes, no tiene ese lado un poco nihilista y ríspido de Baroja y porque su literatura, 150 años después de haber sido escrita, todavía conmueve a mucha gente y no irrita a nadie puesto que en todas sus novelas, incluso en los momentos más trágicos, tristes o melancólicos siempre hay un apunte de humor, de bondad, o de simpatía. Por lo que se refiere a cuál de sus obras es la más galdosiana, no sabe cuál podría responder a este calificativo, aunque para ello recurre a un elogio que le hizo en su día el pintor Ramón Gaya -muy galdosiano también- cuando publicó La malandanza que, por pudor no puede repetir, pero que tenía que ver con Galdós.

La malandanza es una novela que tiene como marco una ciudad, Madrid y una época, unos días de agosto de 1978. Su trama es "una trama de vidas pobres", como señaló en su presentación Justo Navarro (El País, jueves 23-V-1996), en la que "sus personajes no guardan rencor a nadie, lo viven todo con humor, no juzgan ni condenan" en palabras de su autor. Y esos personajes como el de Vicky, la puta; como ese juguete roto, boxeador sonado, Amed Durán; como la pareja formada por Varilla y Melero, uno eléctrico, el otro ayudante del ayudante del ayudante de dirección, primero en el cine, después en la televisión; son unos antihéroes, unos perdedores. Como la pareja protagonista se salva, la novela queda abierta a futuras incursiones, a modo de "episodios nacionales de la transición".

Nosotros destacaríamos otra novela de Trapiello, Ayer no más (https://litenatura.blogspot.com/2014/03/ayer-no-mas-de-andres-

trapiello.html) que trata de las cicatrices que dejó la Guerra Civil en la sociedad española, cicatrices que todavía permanecen hoy, a pesar de 
haber pasado tantos años desde la terminación de esa contienda. La historia parte de un encuentro fortuito del protagonista y su padre con un superviviente de la Guerra, que reconoce en este último a uno de los hombres que en la Fonfría formaba parte del grupo que mató a su padre en 1936. A partir de ahí surgen una serie de conflictos que tomarán unos derroteros desproporcionados en el contexto de la Ley de Recuperación de la Memoria Histórica en el León de nuestra época. La relación entre el protagonista -un profesor universitario de Historia especializado en la Guerra Civil- y su padre -un falangista, participante activo en esa guerra-, ya de por sí difícil, empeorará de manera considerable. No sólo romperá con él, sino con toda su familia y con el Departamento al que pertenece. El sentimiento de culpa, la incomprensión, la falsedad y el deseo de manipulación de la verdad de lo que realmente ocurrió son algunos de los temas que aparecen en este relato en el que su autor intenta ser neutral -rasgo presente en el Galdós de los Episodios- y en el que despliega su amplio dominio de la lengua española.

Manuel Longares, por su parte, se define más lector que escritor gáldosiano en el sentido de que ha leído muchas más obras de Galdós que las que ha podido escribir haciéndose a sus maneras. Se siente, eso sí, participante de una tradición en la que Galdós está muy presente y reconoce que la descripción que hace don Benito al principio de Fortunata y Jacinta de las tiendas de paños de Madrid y su evolución, sí que le ha podido influir en la descripción que él hace del comercio madrileño de la calle Serrano en su novela Romanticismo, amplio fresco sobre la burguesía madrileña del barrio de Salamanca durante la Transición española que entronca, por su manera de concebir la novela, con Cervantes, Galdós, Dickens o Dostoyevski.

Elvira Lindo también se reconoce más galdosiana como lectora, aunque piensa que se le ha contagiado de Galdós su facilidad para hacer hablar a los personajes, la ironía, el sentido del humor y ese don que tenía para situar a los personajes en lugares concretos. En ese sentido cree que nuestro autor la ha ayudado bastante porque le ha quitado el complejo que sentía de escribir de manera muy local. Destaca Tristana como su novela galdosiana preferida por varias razones y señala que le influyó mucho al escribir Una palabra tuya, cuya trama gira en torno a Rosario y Milagros, dos barrenderas que se conocen desde niñas. Esta obra es el retrato de dos mujeres, de dos proyecciones de un mismo espejo deformante, de dos trayectorias vitales, una hacia la nada más cruel desde una vida triste y la otra hacia un futuro expectante desde una vida redimida; y en medio, la piedad y el perdón.

Care Santos se confiesa devota lectora galdosiana porque es novelista y un novelista no puede vivir al margen de la influencia y maestrazgo que ejerció Benito Pérez Galdós. Reconoce que algunas de sus novelas no habrían existido de la manera que son si no hubiera leído alguna obra del 
escritor grancanario justamente cuando se preparaba para escribirlas. Elige como la más galdosiana de sus novelas El aire que respiras que es una obra de homenaje al Romanticismo español en la que aparece un momento histórico -la invasión napoleónica-, que don Benito trató, cuyos personajes se inspiraron en la mirada y el tratamiento que este autor les dio.

\section{4.- OBRAS CITADAS}

(1889) ALAS "CLARÍN", Leopoldo, Benito Pérez Galdós: estudio críticobiográfico, Est. Tip. de Ricardo Fe, Madrid. Biblioteca Virtual Miguel de Cervantes, Alicante, 2001.

(2020) ARENCIBIA, Yolanda, Galdós. Una biografía. Tusquets Editores, Barcelona.

(1977) BLANQUAT, Josette, "¿Galdós, humanista". En V.V.A.A., Actas del I Congreso Internacional de Estudios Galdosianos, Cabildo Insular de Gran Canaria, Las Palmas de Gran Canaria, pp. 43-59.

(1970-1971) JUTGLAR, Antoni, "Sociedad e Historia en la obra de Galdós". En Cuadernos Hispanoamericanos, núm. 250-251-252, pp.242-256. Biblioteca Virtual Miguel de Cervantes, Alicante, 2012.

(2016) MARSÉ, Juan, Esa puta tan distinguida. Lumen, Barcelona.

(1993) SÁNCHEZ- GEY, Juana, "Galdós y la filosofía del siglo XIX. EI humanismo de la Tía Roma". En V.V.A.A., Actas del IV Congreso Internacional de Estudios Galdosianos (1990), Cabildo Insular de Gran Canaria, Las Palmas de Gran Canaria, vol. II, pp. 549-557. 